\title{
Mutational analysis of pulmonary tumours with neuroendocrine features using targeted massive parallel sequencing: a comparison of a neglected tumour group
}

Claudia Vollbrecht ${ }^{1,8}$, Robert Werner ${ }^{2}$, Robert Fred Henry Walter ${ }^{2,3}$, Daniel Christian Christoph ${ }^{4}$, Lukas Carl Heukamp ${ }^{1,9}$, Martin Peifer ${ }^{5}$, Burkhard Hirsch ${ }^{6}$, Lina Burbat ${ }^{6}$, Thomas Mairinger ${ }^{7}$, Kurt Werner Schmid ${ }^{2}$, Jeremias Wohlschlaeger ${ }^{2}$ and Fabian Dominik Mairinger ${ }^{\star}, 2,8$

${ }^{1}$ Institute of Pathology, University Hospital Cologne, Cologne, Germany; ${ }^{2}$ Institute of Pathology, University Hospital Essen, University of Duisburg-Essen, Essen, Germany; ${ }^{3}$ Ruhrlandklinik, West German Lung Centre, University Hospital Essen, University of Duisburg-Essen, Essen, Germany; ${ }^{4}$ Department of Oncology, University Hospital Essen, University of Duisburg-Essen, Essen, Germany; ${ }^{5}$ Department of Translational Genomics, Cologne Center of Genomics, University of Cologne, Cologne, Germany; IInstitute of Pathology, Molecular Diagnostics, Charité Universitätsmedizin Berlin, Berlin, Germany and 'Institute of Pathology, Helios Klinikum Emil von Behring, Berlin, Germany

Background: Lung cancer is the leading cause of cancer-related deaths worldwide. The typical and atypical carcinoid (TC and AC), the large-cell neuroendocrine carcinoma (LCNEC) and the small-cell lung cancers (SCLC) are subgroups of pulmonary tumours that show neuroendocrine differentiations. With the rising impact of molecular pathology in routine diagnostics the interest for reliable biomarkers, which can help to differentiate these subgroups and may enable a more personalised treatment of patients, grows.

Methods: A collective of 70 formalin-fixed, paraffin-embedded (FFPE) pulmonary neuroendocrine tumours (17 TCs, 17 ACs, 19 LCNECs and 17 SCLCs) was used to identify biomarkers by high-throughput sequencing. Using the Illumina TruSeq Amplicon-Cancer Panel on the MiSeq instrument, the samples were screened for alterations in 221 mutation hot spots of 48 tumour-relevant genes.

Results: After filtering $>26000$ detected variants by applying strict algorithms, a total of 130 mutations were found in 29 genes and 49 patients. Mutations in JAK3, NRAS, RB1 and VHL1 were exclusively found in SCLCs, whereas the FGFR2 mutation was detected in LCNEC only. KIT, PTEN, HNF1A and SMO were altered in ACs. The SMAD4 mutation corresponded to the TC subtype. We prove that the frequency of mutations increased with the malignancy of tumour type. Interestingly, four out of five ATM-mutated patients showed an additional alteration in TP53, which was by far the most frequently altered gene (28 out of $130 ; 22 \%)$. We found correlations between tumour type and IASLC grade for $A T M-(P=0.022 ; P=0.008)$ and TP53-mutated patients $(P<0.001)$. Both mutated genes were also associated with lymph node invasion and distant metastasis $(P \leqslant 0.005)$. Furthermore, PIK3CA-mutated patients with high-grade tumours showed a reduced overall survival $(P=0.040)$ and the mutation frequency of $A P C$ and ATM in high-grade neuroendocrine lung cancer patients was associated with progression-free survival (PFS) $(P=0.020)$.

Conclusions: The implementation of high-throughput sequencing for the analysis of the neuroendocrine lung tumours has revealed that, even if these tumours encompass several subtypes with varying clinical aggressiveness, they share a number of molecular features. An improved understanding of the biology of neuroendocrine tumours will offer the opportunity for novel approaches in clinical management, resulting in a better prognosis and prediction of therapeutic response.

*Correspondence: Dr FD Mairinger; E-mail: fabian-dominik.mairinger@charite.de

${ }^{8}$ Current address: Institute of Pathology, Molecular Diagnostics, Charité Universitätsmedizin Berlin, Hindenburgdamm 30, D-12200 Berlin, Germany.

${ }^{9}$ Current address: Institute for Hematopathology Hamburg, Hamburg, Germany.

Received 6 August 2015; revised 14 October 2015; accepted 15 October 2015; published online 8 December 2015

(c) 2015 Cancer Research UK. All rights reserved 0007-0920/15 
Lung cancer is the leading cause of cancer-related deaths worldwide, with $15 \%$ of cases showing only a 5 -year survival rate. Nearly one-fourth of all lung neoplasms originate from cells of the diffuse neuroendocrine system and are classified as neuroendocrine tumours (NET) (Rekhtman, 2010). This spectrum of neoplasms is composed of the high-grade small-cell lung cancer (SCLC), the large-cell neuroendocrine carcinoma (LCNEC), as well as the lowgrade typical (TC) and atypical carcinoids (AC) (Takei et al, 2002).

Although smoking is not correlating with carcinoids, most of LCNEC and all SCLC patients exhibit a smoking history (Travis, 2009; Swarts et al, 2012). Even though tumours are detected at an early stage, SCLCs and LCNECs show the poorest clinical outcome as compared with other lung tumours because of their high malignancy (Takei et al, 2002). The 5-year survival rate of patients with SCLC is $<5 \%$ (Rekhtman, 2010). The same holds true for LCNECs that show a similar progression with 5-year survival rates varying from $15 \%$ up to $57 \%$, depending on the source of information (Asamura et al, 2006; Rekhtman, 2010). In contrast, patients suffering from TC show excellent survival rates of up to $100 \%$. Nevertheless, some of them present with lymph node metastasis (4-15\%) (Travis et al, 1998; Beasley et al, 2000; Fink et al, 2001; Thomas et al, 2001; Cardillo et al, 2004; Pelosi et al, 2005; Asamura et al, 2006; Garcia-Yuste et al, 2007; Rea et al, 2007; Travis, 2009). Atypical carcinoids are more aggressive and show a higher frequency of nodal metastasis (35-64\%) with decreased survival rates ranging from $61 \%$ to $88 \%$ (Beasley et al, 2000; Fink et al, 2001; Scott, 2003; Cardillo et al, 2004; Pelosi et al, 2005; Asamura et al, 2006; Garcia-Yuste et al, 2007; Rea et al, 2007).

During lung carcinogenesis, cells stepwise accumulate multiple genetic and epigenetic abnormalities that lead to immortalisation, uncontrolled proliferation and spread of these altered cells (Brambilla et al, 2003). This is often initiated by the presence of mutations, but can also be an effect of chromosomal aberrations (Esteller et al, 1999; Zochbauer-Muller et al, 2001). In particular, the most common mutated gene in lung cancer is the tumour suppressor TP53, encoding a protein that induces cell growth arrest and apoptosis and mediates cell cycle regulation. In contrast to pulmonary carcinoids, which are rarely TP53 altered, up to $50 \%$ of non-small-cell lung cancer (NSCLC) and $>70 \%$ of SCLCs were associated with mutations in this gene (Travis et al, 2004). In addition, the crucial retinoblastoma (RB) pathway is often inactivated. Up to $100 \%$ of high-grade NETs like SCLCs or LCNECs are affected by the loss of the RB protein (Travis et al, 2004).

The advent of next-generation sequencing (NGS) systems allows a very sensitive analysis of multiple patients and targets simultaneously. Therefore, further mutational analysis of neuroendocrine lung tumours by a high-throughput sequencing approach helps to gain more insight into their genetic profile, enabling a further subdivision of these different groups. Here we subjected, for the first time, 70 neuroendocrine lung tumours to a targeted NGS approach based on sequencing-by-synthesis chemistry, feasible for formalin-fixed, paraffin embedded (FFPE) material.

\section{MATERIALS AND METHODS}

Demographic data and study design. The study is based on a collective of 70 representative, FFPE neuroendocrine lung tumours (17 TCs, 17 ACs, 19 LCNECs and 17 SCLCs) used for massive parallel sequencing purposes. The initial diagnosis was re-evaluated by two experienced pathologists (JW and TM). Inclusion criteria were sufficient tumour material (tumour cell count 50-80\%) and a minimum of contamination by lymphocytic and stromal cells. All analysed cases comprise surgical resection. The surgical resected SCLCs were resected as initial unknown tumoural lesion and were afterwards diagnosed as SCLC. All investigated SCLCs were classified as limited or very limited diseases (VLDL). Specimens were collected at the Institute of Pathology at the University Hospital Essen (Essen, Germany) from 2005 till 2012. The TNM staging was based on the WHO Classification Of Tumours guidelines (2004) (Travis et al, 2004)). The mean age at date of diagnosis was 58.6 years (median age: 59.0 years; 95\% CI: 50.8-66.9 months). Survival data were available for 34 patients with 12 reported deaths at the time of data collection. Survival data were collected for the highgrade group as well as overall survival (OS) for 3 carcinoid tumours showing an aggressive course with reported death after 4.4, 7.3 and 11.3 months, respectively. For the remaining carcinoids, no survival data were collected because of their excellent prognosis.

The study was conducted retrospectively for the identification of biomarkers. Patients who received chemotherapy before resection of tumour tissue specimens were excluded. The study was approved by the ethical committee of the University Hospital Essen (ID: 13-5382-BO). The investigations conform to the principles outlined in the declaration of Helsinki. Patient characteristics are summarised in Table 1.

DNA extraction. For DNA isolation, FFPE tissue slides of $4 \mu \mathrm{m}$ were prepared using a microtome Cool Cut HM 355S (MICROM International, Walldorf, Germany). Three to five paraffin tissue slides per sample were deparaffinised with xylene before DNA extraction. Genomic DNA was isolated via Maxwell 16 Research (Promega, Madison, WI, USA) as recommended by the manufacturer. Following, DNA quantification was performed using

Table 1. Patient characteristics

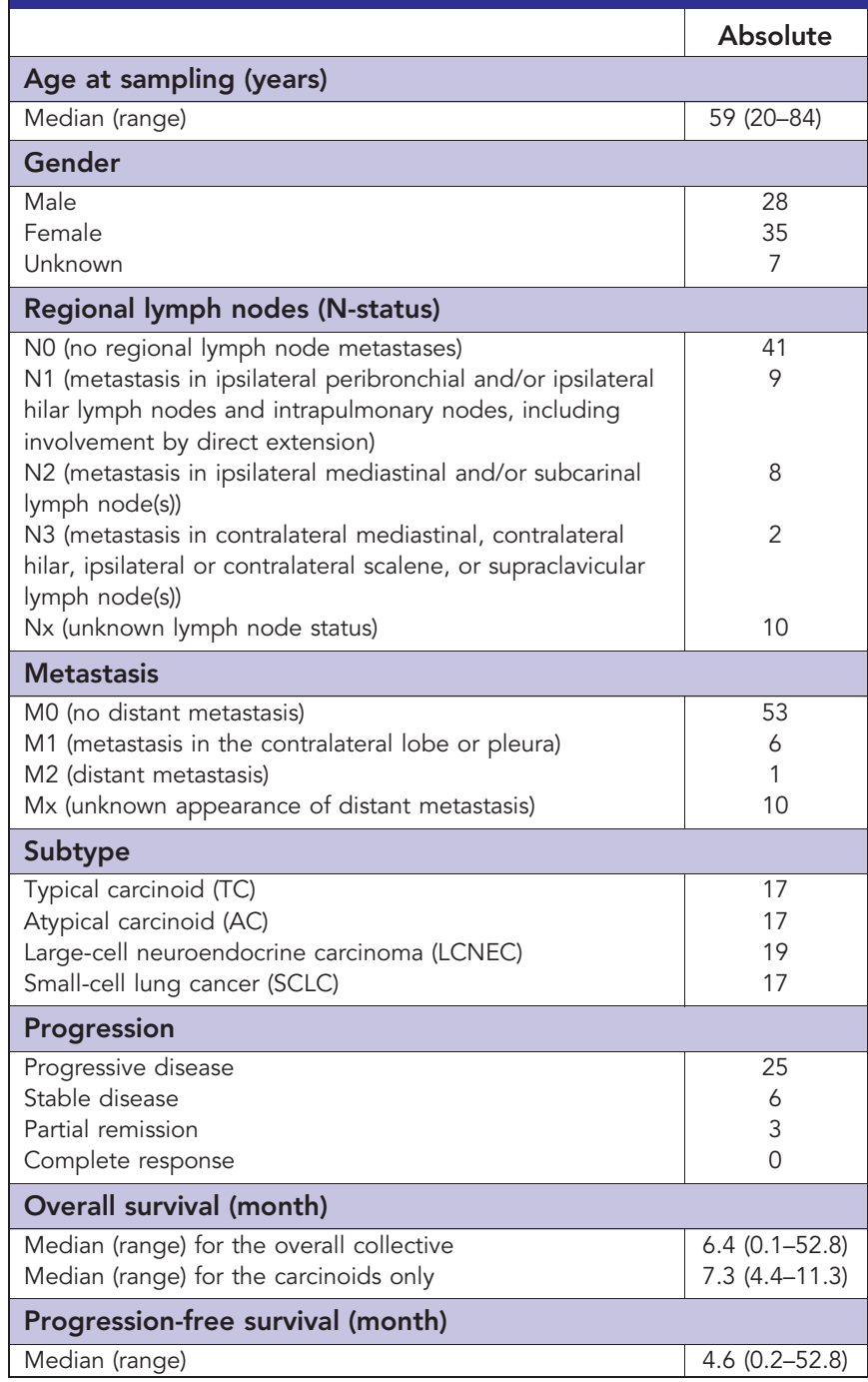


Nanodrop ND-1000 (Thermo Fisher Scientific, Waltham, MA, USA) and Qubit (Life Technologies, Carlsbad, CA, USA).

Targeted next-generation sequencing. Sample preparation was done using the TruSeq Amplicon-Cancer Panel (Illumina, San Diego, CA, USA). Therefore, 424 target-specific probes, covering 221 mutation hot spots of 48 tumour-relevant genes, were used to capture the regions of interest (Table 2). Furthermore, each sample was labelled with a barcode sequence consisting of eight individual nucleotides, in a final PCR step. A total of 212 amplicons per sample with a mean length of 180 base pairs were sequenced paired-end on the MiSeq instrument (Illumina) using the v1 chemistry. Sample preparation and sequencing procedure was performed according to the standard protocols provided by the manufacturer.

Sequencing data analysis. Fastq files generated by the MiSeq reporter software (Illumina) were used for further analysis with a customised bioinformatics pipeline based on the general cancer genome analysis algorithm published by Peifer et al (2012).

Subsequently, data filtering was done by excluding variants with $<25$ effective reads (total reads $\times$ (percent variant reads/100)) and by excluding variants with $<5 \%$ allele frequency. Afterwards, synonymous alterations were removed and visual analysis of called variants was performed by means of the Integrative Genomic Viewer (IGV, Broad Institute, Cambridge, MA, USA). False positive variants, particularly in repetitive or highly homologous regions of the genome, variants in high background noise, as well as singlestrand variants, were eliminated when they were clearly recognisable as artefacts. Finally, obtained variants were analysed for their functional impact on the protein by MutationAssessor (http:// mutationassessor.org, release 2) (Reva et al, 2011) and Variant Effect Predictor (VEP, Ensembl release 78) (McLaren et al, 2010) implementing the bioinformatics tools SIFT (sorting intolerant from tolerant) (Kumar et al, 2009) and PolyPhen2 (polymorphism phenotyping v2) (Adzhubei et al, 2010). Only mutations with a functional impact as determined by at least two of the three applied algorithms as well as frameshift deletions/insertion and alterations leading to a stop codon were used for statistical analysis.

Statistical analysis. All statistical analyses were performed using the $\mathrm{R}$ environment for statistical computing and graphics (R Foundation, Vienna, Austria). For dichotomous factors and linear vectors the Wilcoxon Mann-Whitney rank sum test was applied. For variance analysis of variables with more than two categories, the Kruskal-Wallis test was performed. Double dichotomous contingency tables (e.g., mutational status to lymph node invasion status) were analysed using Fisher's exact test. To test dependence of ranked parameters with more than two groups (e.g., mutational status and tumour type) Pearson's $\chi^{2}$ test was used. Kaplan-Meier analysis was performed to test associations between mutation status and OS as well as progression-free survival (PFS). The PFS was calculated from the first day of chemotherapy until radiologic progression, death from any cause or the last time of follow-up without progression. Overall survival was defined as the time from date of diagnosis until the date of death or last follow-up. Patients were censored at the last follow-up if still alive or loss of follow-up. Surveillance of PFS and OS was stopped on 31 August 2014. Significant differences in PFS or OS between groups were verified by the Wald test, likelihood ratio test and Score (logrank) test (Supplementary Table S3). The level of statistical significance was defined as $P \leqslant 0.05$.

\section{RESULTS}

Run parameters and sequencing quality. A total of 70 neuroendocrine lung cancers were sequenced with $4 \mathrm{MiSeq}$ runs, containing 23 or 24 samples per run. Samples showing coverages with $<250$ median read counts per amplicon (23 out of 70 ) were resequenced with an additional fifth run.

Bridge amplification of the target regions on the flow cell resulted in an average cluster density of $641 \mathrm{~K} \mathrm{~mm}^{-2}$ with $\sim 80 \%$ of the generated clusters passing the quality filter parameters. In total, the sequencing runs produced an average of $3.65 \times 10^{6}$ reads and an average output of 1.1 gigabases. The runs showed read quality parameters with average Q30 scores (equals a $0.1 \%$ chance of a wrong base call at this position) of $\sim 63 \%$ in a range of $8-85 \%$ (Supplementary Table S1). Approximately $60 \%$ of the targets showed coverages between 500 and 2000 reads (Supplementary Figure S1).

Variant filtering and mutation detection. The sequencing analysis of all five runs revealed a total of 26945 variants. Removal of variants with $<25 \%$ effective reads and variants with $<5 \%$ allele frequency resulted in 643 variants. Finally, additional removal of variants clearly recognised as artefacts resulted in 254 variants that were further analysed according to their functional relevance, leading to a total of 130 mutations in 29 genes (Table 3) detected in 49 of 70 FFPE neuroendocrine lung tumour samples (Figure 1 and Supplementary Table S2). No variants were found in the remaining 19 genes.

The mutation status of some genes was associated with a special subtype of the pulmonary NETs (Table 3 and Figure 2A). Mutations in JAK3 (exon 16: p.W690*), NRAS (exon 2: p.G13D, p.S17N), RB1 (exon 18: p.P595L; exon 20: H673Y) and VHL1 (exon 3: Q164*) were exclusively found in SCLCs, whereas the detected FGFR2 mutation p.A264T in exon 7 was only associated with LCNEC. The KIT (exon 10: p.K546delinsGG; exon 13 p.M638fs), PTEN (exon 8: p.P339S), HNF1A (exon 4: p.G288fs) and SMO (exon 5: p.L367R) alterations were only found in ACs and the SMAD4 (exon 5: p.Q169*, exon 5) mutation corresponded to the TC subtype.

Furthermore, the total mutation frequency increased with the malignancy of the tumour type. Of the 130 mutations, 11 (9\%) were related to TCs (mean: 0.6 per sample), 21 (16\%) were found in ACs (mean: 1.2 mutations per sample) and 38 (29\%) were related to LCNECs (mean: 1.9 per sample). Patients associated to SCLC showed the highest mutation frequency of $46 \%$ with 60 detected mutations (mean: 3.5 per sample). This effect was especially observed for ATM, ERBB2, ERBB4, PIK3CA, RET and TP53 (Figure 2B). Interestingly, four of five ATM mutated patients

Table 2. Genes included in the TruSeq Amplicon-Cancer Panel (Illumina)

\begin{tabular}{|l|l|l|l|l|l|l|l|}
\hline ABL1 & AKT1 & ALK & APC & ATM & BRAF & CDH1 & CDKN2A \\
\hline CSF1R & CTNNB1 & EGFR & ERBB2 & ERBB4 & FBXW7 & FGFR1 & FGFR2 \\
\hline FGFR3 & FLT3 & GNA11 & GNAQ & GNAS & HNF1A & HRAS & IDH1 \\
\hline JAK2 & JAK3 & KDR & KIT & KRAS & MET & MLH1 & MPL \\
\hline NOTCH1 & NPM1 & NRAS & PDGFRA & PIK3CA & PTEN & PTPN11 & RB1 \\
\hline RET & SMAD4 & SMARCB1 & SMO & SRC & STK11 & TP53 & VHL \\
\hline \multicolumn{7}{l}{ The panel consists of 2 212 probes covering 221 mutation hot spots in 48 genes known to be important in human cancerogenesis. } \\
\hline
\end{tabular}


Table 3. Distribution of mutations between the different tumour subtypes

\begin{tabular}{|l|c|c|c|c|}
\hline & TC (\%) & AC (\%) & LCNEC (\%) & SCLC (\%) \\
\hline JAK3 $(n=1)$ & 0 & 0 & 0 & 100 \\
\hline NRAS $(n=2)$ & 0 & 0 & 0 & 100 \\
\hline RB1 $(n=2)$ & 0 & 0 & 0 & 100 \\
\hline VHL $(n=1)$ & 0 & 0 & 0 & 100 \\
\hline ATM $(n=7)$ & 0 & 0 & 14 & 86 \\
\hline TP53 $(n=31)$ & 0 & 0 & 48 & 52 \\
\hline ALK $(n=2)$ & 0 & 0 & 50 & 50 \\
\hline BRAF $(n=3)$ & 0 & 0 & 67 & 33 \\
\hline FGFR2 $(n=1)$ & 0 & 0 & 100 & 0 \\
\hline PIK3CA $(n=8)$ & 0 & 13 & 13 & 75 \\
\hline ERBB4 $(n=5)$ & 0 & 20 & 40 & 40 \\
\hline KDR $(n=3)$ & 0 & 33 & 67 & 0 \\
\hline KRAS $(n=3)$ & 0 & 33 & 67 & 0 \\
\hline MET $(n=3)$ & 0 & 33 & 67 & 0 \\
\hline SMARCB1 $(n=2)$ & 0 & 50 & 0 & 50 \\
\hline FGFR1 $(n=2)$ & 0 & 50 & 50 & 0 \\
\hline KIT $(n=2)$ & 0 & 100 & 0 & 0 \\
\hline PTEN $(n=1)$ & 0 & 100 & 0 & 0 \\
\hline SMO $(n=1)$ & 0 & 100 & 0 & 0 \\
\hline HNF1A $(n=1)$ & 0 & 100 & 0 & 0 \\
\hline RET $(n=7)$ & 14 & 14 & 14 & 58 \\
\hline EGFR $(n=7)$ & 14 & 29 & 14 & 43 \\
\hline APC $(n=7)$ & 14 & 29 & 14 & 43 \\
\hline ERBB2 $(n=11)$ & 18 & 18 & 27 & 36 \\
\hline ABL1 $(n=5)$ & 20 & 0 & 40 & 40 \\
\hline PDGFRA $(n=4)$ & 25 & 0 & 25 & 50 \\
\hline IDH $(n=5)$ & 40 & 0 & 0 & 60 \\
\hline GNAS $(n=2)$ & 50 & 50 & 0 & 0 \\
\hline SMAD4 $(n=1)$ & 100 & 0 & 0 & 0 \\
\hline Abbreviations: AC $=$ atypical carcinoid; LCNEC = large-cell neuroendocrine carcinoma; SCLC $=$ \\
small-cell lung cancer; TC=typical carcinoid. JAK3, NRAS, RB1 as well as VHL variants were \\
exclusively found in SCLCs, whereas the FGFR2 mutation was only detected in LCNEC. The KIT, \\
PTEN and SMO alterations were determined in ACs and the SMAD4 variant in TC subtype only.
\end{tabular}

also showed an alteration in the tumour suppressor TP53, and this was by far the most frequently altered gene (31 out of $130 ; 24 \%$ ) followed by ERBB2 (11 out of 130, 9\%), PIK3CA with 8 (6\%) and EGFR present with 7 mutations (5\%).

We found significant correlations between tumour type and IASLC grade for ATM $(P=0.022 ; P=0.008)$ and TP53 mutated patients $(P>0.001 ; P<0.001)$. In addition, TP53 showed significant more multiple mutations $(P<0.001)$. Both genes were also associated with lymph node invasion and distant metastasis when they were mutated (both $P \leqslant 0.005$ ).

Moreover, the frequency of variants in ATM and APC in highgrade neuroendocrine lung cancer patients was associated with PFS $(P=0.020$; Figure $3 \mathrm{~A})$. Finally, PIK3CA mutated patients with high-grade tumours showed a reduced OS compared with their wild-type counterparts $(P=0.040$; Figure $3 \mathrm{~B})$.

\section{DISCUSSION}

In contrast to NETs of other organ systems (e.g., gastrointestinal), pulmonary NETs form two prognostically different groups: the low-grade carcinoid tumours (TC and AC) and the high-grade carcinomas (LCNEC and SCLC) (Rindi et al, 2014). The detailed molecular characteristic of these subgroups still remains unknown.

Here, for the first time, we describe a targeted high-throughput parallel sequencing approach used to analyse 70 neuroendocrine lung tumours for alterations in 221 hot spots of 48 genes suspected to play an important role in the tumourigenesis. Entity-specific mutations identified by this method can potentially serve as markers for classification of neuroendocrine lung tumours in diagnostics or therapy decision.

Our data confirm previous findings (Lohmann et al, 1993; Przygodzki et al, 1996; Couce et al, 1999; Leotlela et al, 2003; Swarts et al, 2012), showing that mutations in the TP53 gene increase with malignancy of the tumour subtype. The TP53 alterations detected in this study ranged from none in carcinoid tumours to 11 in the 17 analysed SCLC samples. Interestingly, the same trend was observed for ATM mutations. Furthermore, four out of five ATM mutated patients showed co-alterations in TP53 (Figure 1). ATM is a serine/ threonine kinase that coordinates an integrated cellular response to DNA damage by double-stranded DNA breaks and acts upstream of TP53 where it leads to the activation of an apoptotic pathway (Pettitt et al, 2001). Furthermore, it activates several TP53-independent cellular pathways and it is conceivable that mutations in both genes could increase the survival advantage of a malignant tumour cell clone. Subsequently, additional mutations in $A P C$, which is a downstream target of TP53, could possibly enhance the survival benefit for certain tumour subclones. Actually, two out of seven APC mutations detected in our study were observed coincidentally with an ATM or with ATM and TP53 mutations, pointing out a second or third hit mechanism during tumourigenesis.

Interestingly, the group of R Thomas (Fernandez-Cuesta et al, 2014) identified mutations in genes related to chromatin remodelling (including $M E N 1, A R I D 1 A$ and $E I F 1 A X)$ as frequent events in pulmonary carcinoids. In addition, mutations in the histone methyltransferases (including SETD1B, SETDB1 and NSD1) as well as demethylases (KDM4A, PHF8, JMJD1C and others) were determined (Fernandez-Cuesta et al, 2014). Likewise, his working group proofed the appearance of CREBBP and EP300 histone acetyltransferases as well as the histone-modifying enzyme MLL in high-grade lung cancers in another study (Peifer et al, 2012), indicating that histone modifications play a crucial role in neuroendocrine lung cancer tumourigenesis and progression.

Activating mutations in the EGFR gene have been widely studied in NSCLC (Engle and Kolesar, 2014; Karachaliou and Rosell, 2014; Revannasiddaiah et al, 2014). Unfortunately, although new therapeutic strategies are urgently needed for metastatic pulmonary carcinoid tumours, this subgroup of lung neoplasia is totally neglected, so far. Instead of common activating EGFR mutations, we found alterations located in the TOPO domain in all four tumour subtypes. In particular, the p.A859V in exon 21 may activate the EGF receptor similarly to the well-known therapeutically relevant activating p.L858R mutation (Peng et al, 2014). Of note, in one patient we observed that EGFR mutations were located in different regions of the gene. Importantly, these complex events are also under suspicion to predict a response to tyrosine kinase inhibitor (TKI) therapy (Peng et al, 2014).

Similar to EGFR, both other investigated members of the ERBB superfamily (ERBB2 and ERBB4) also showed mutations in the extracellular TOPO domain (11 samples; 2 TCs and ACs, 3 LCNECs and 4 SCLCs). In addition, the growth factor receptor PDGFRA is impaired in four samples (one TC, one LCNEC and two SCLCs). Furthermore, KDR (VEGFR2) is mutated in one AC and two LCNECs. Of note, KDR p.Q427H variant in exon 11, located in the protein kinase domain, occurred in approximately one-third of all carcinoids and the half of all investigated carcinomas. Although all three applied algorithms predicted a benign or tolerated alteration of 
Malignancy of tumour subtype

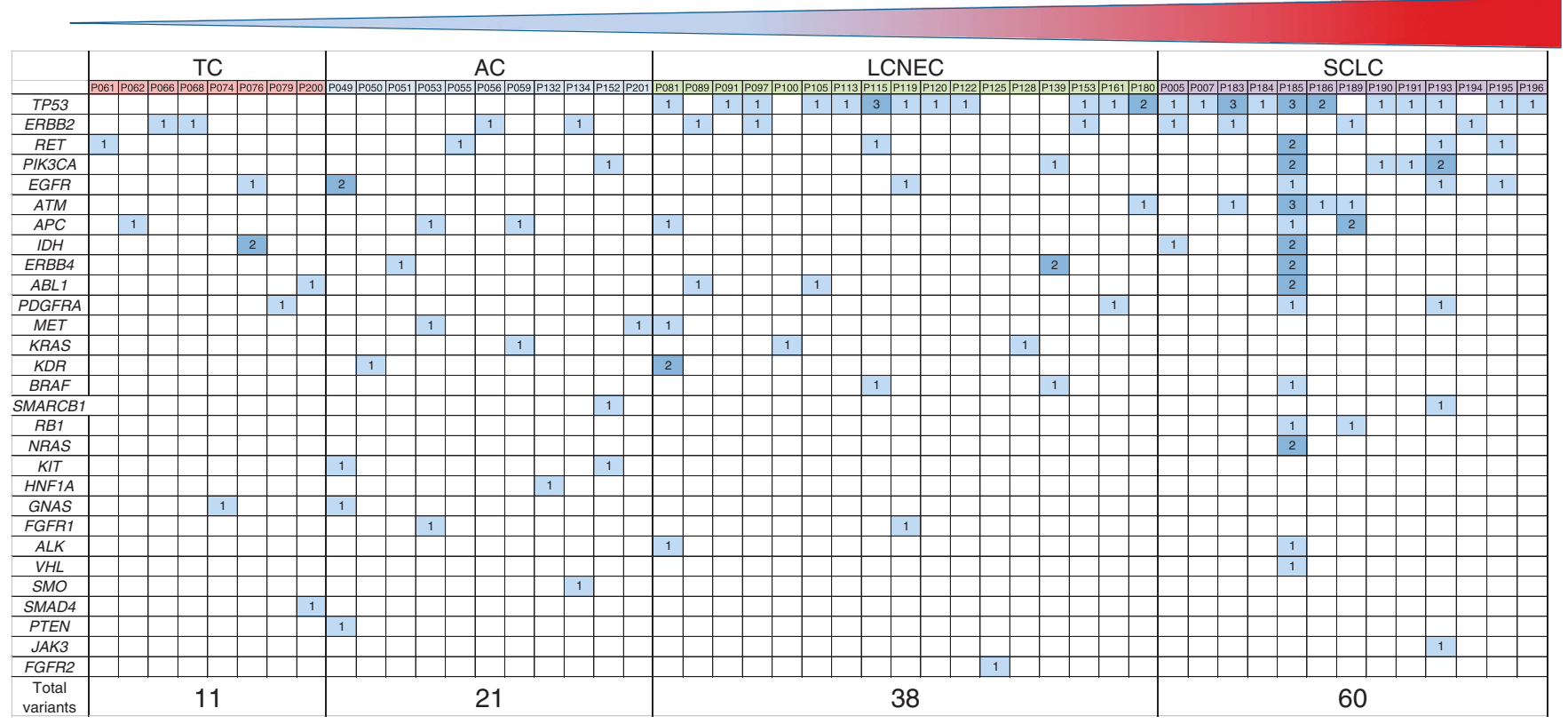

Mutation frequency

Figure 1. Genetic profile of four analysed neuroendocrine lung tumour subtypes carrying gene mutations determined by targeted massive parallel sequencing are shown. Columns represent mutations per patient; rows summarise mutations occurring in a particular gene. Dark blue boxes indicate more than one mutation per patient in the corresponding gene.

A
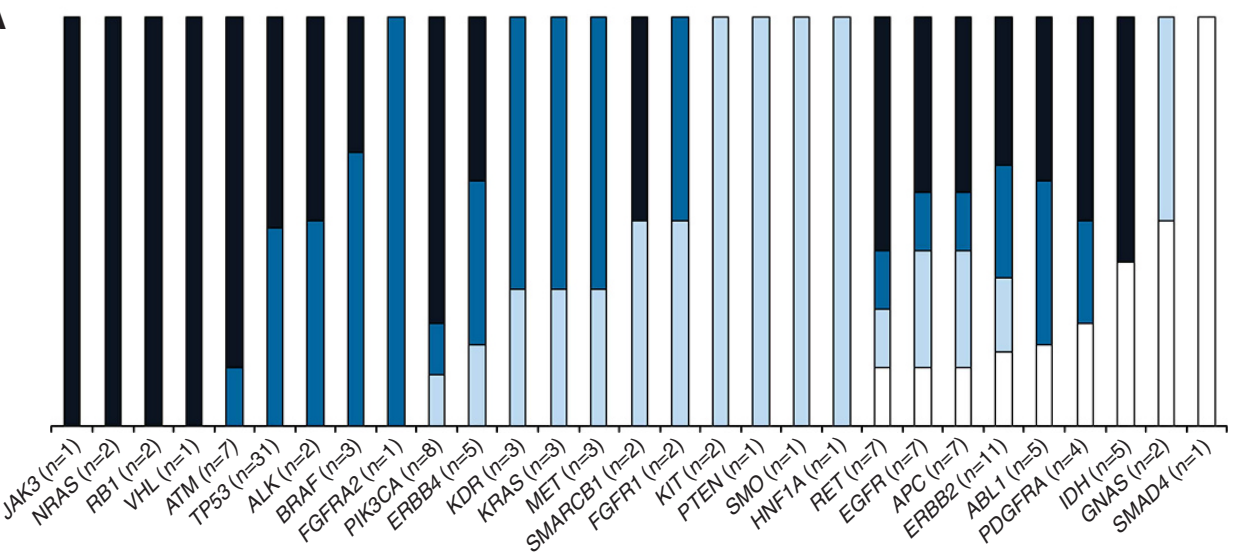

B

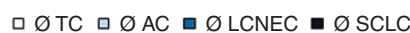

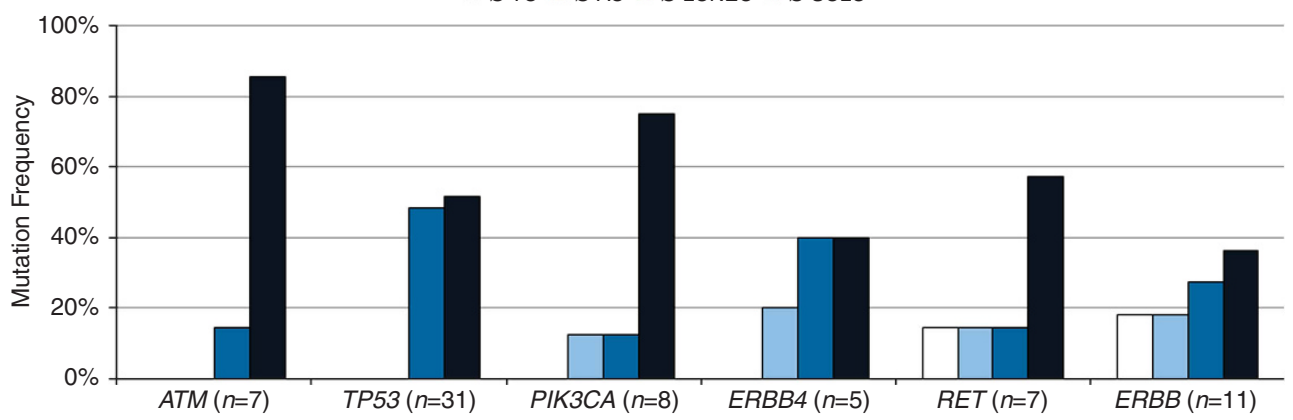

Figure 2. (A) Genes within entity-specific mutation frequency are shown. The JAK3, NRAS, RB1 and VHL variants were just detected in SCLCs, whereas ATM, TP53, ALK and BRAF mutations were found in both high-grade tumour entities. The FGFR2 mutation occurred exclusively in LCNEC. The KIT, PTEN, HNF1A and SMO variants were only found in ACs, and the SMAD4 variant was only present in TC. The GNAS mutations were limited to carcinoids. (B) Specific genes showing a higher mutation frequency with increasing tumour malignancy. The bars indicate the distribution of the mutation between the different tumour entities. The TP53 and ATM variants were just detected in high-grade tumours with ATM variants mostly in SCLCs; PIK3CA and ERBB4 showed additional variants in AC; RET mutations were present in all four entities, but mainly in SCLCs, whereas ERBB2 showed an increasing mutation frequency with an increase of the tumour malignancy. 

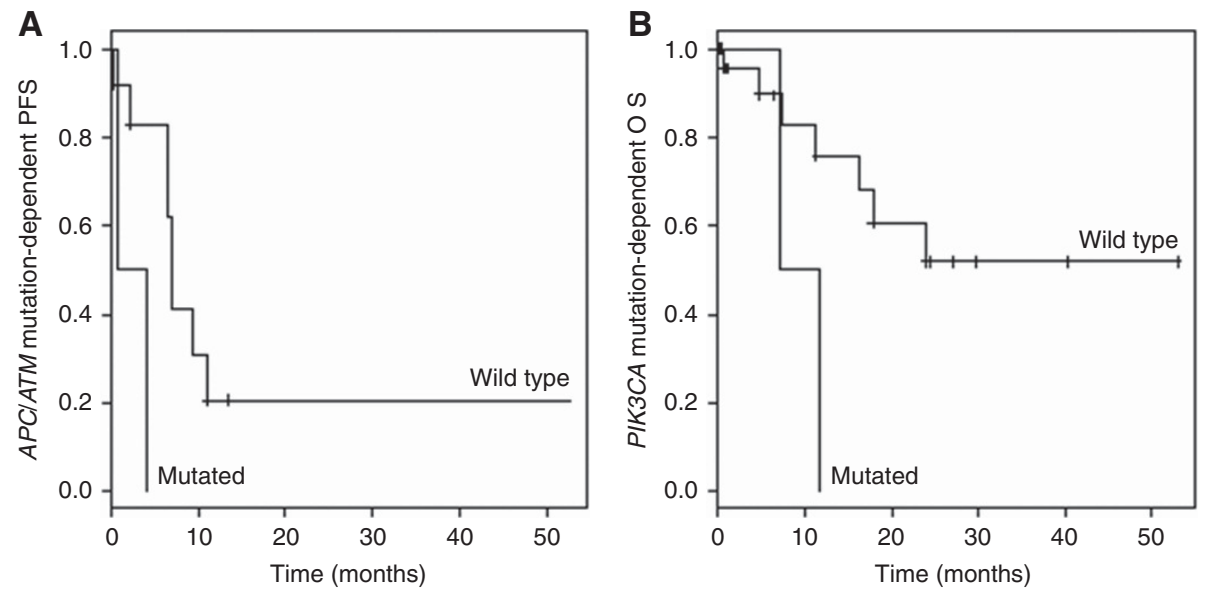

Figure 3. Kaplan-Meier curves for progression-free survival (PFS) (A) and overall survival (OS) (B) differentiated by the patients' mutational status are shown. Because of the excellent survival rate of pulmonary carcinoids, only high-grade cases are depicted. Of note, samples had mutations in both ATM and APC, showing an association to PFS $(P=0.020)$. The relation of this double mutation has to be clarified. The PIK3CA mutated patients with high-grade tumours showed a reduced OS compared with their wild-type counterparts $(P=0.040)$.

the protein, the KDR p.Q427H mutation is reported to be associated with an increased risk of coronary heart disease and has been detected in patients with NSCLC (Wang et al, 2007; Glubb et al, 2011). Glubb et al (2011) demonstrated that this alteration can modestly increase VEGFR-2 signaling and may be also associated with increased lung tumour vascularisation. The high proportion of neuroendocrine lung tumours showing this alteration underlines the hypothesis that it might be a potential marker for future risk assessment in a diagnostic setting.

Interestingly, downstream of these receptor tyrosine kinases, well-known activating mutations were observed in both NRAS and KRAS. Pathway activation downstream of EGFR, for example, by KRAS mutations, is known to be a resistance mechanism for EGFR-TKI therapeutic approaches (Engelman et al, 2006). Activation downstream of $B R A F$, primary by NRAS mutations, is reported to act as a potential resistance mechanism against vemurafenib therapy (Sos et al, 2014). Even continued activation of PI3K signalling by a PIK3CA oncogenic mutant was shown to be sufficient to abrogate gefitinib-induced apoptosis (Engelman et al, 2006). Additional studies confirmed mutations in the PI3K pathway to be involved in different EGFR resistance mechanisms (Sequist et al, 2011). Such mutations were detected in our cohort of NETs including variants affecting the C2-PI3K domain as well as the PI3K-ABD domain and the PI3K/PI4K domain of the PIK3CA gene locus. Our findings bear analogy to the previously published results of Capodanno et al (2012) who also found PIK3CA mutations in neuroendocrine lung cancers correlated to an increase of entities' malignancy. In contrast to our present study, the frequency of mutations detected by Capodanno et al (2012) is as twice as high, mainly consisting of $\mathrm{C}: \mathrm{G}>\mathrm{T}: \mathrm{A}$ transversions $(>81 \%)$. Considering the use of FFPE material, this high mutation frequency has to be assessed critically. To overcome this problem, we assessed a very stringent filtering mechanism for data analysis to avoid fixation artefacts.

The RET proto-oncogene, a member of the cadherin superfamily, encodes a receptor tyrosine kinase. Mutations in this gene are associated with the disorders multiple endocrine neoplasia (MEN) type IIA and IIB and medullary thyroid carcinoma (Krampitz and Norton, 2014). In line with previous findings in other endocrine tumour entities (Rotondi et al, 2009; Schulte et al, 2010; Colombo et al, 2015; Yeganeh et al, 2015), we determined $R E T$ variants in $\sim 9 \%$ (6 out of 70) of pulmonary NET patients. By the way, the activating p.M918T RET mutation was previously assessed in one metastatic SCLC specimen (Dabir et al, 2014). In contrast, Futami et al (2003) could not proof mutations but LOH of RET in the majority of SCLCs. Nevertheless, the analysed collective was very small (8 informative samples) (Futami et al, 2003). In carcinoid tumours, high gene expression of RET was associated with low long time survival but was not proven on protein level and also mutations in the RET oncogene could not be identified in any samples of the study (Swarts et al, 2013). In our collective we found one RET mutation in each TC and AC.

Summing up, the implementation of targeted high-throughput sequencing for the analysis of the neuroendocrine lung tumours has revealed that these tumours, even if they vary in their clinical aggressiveness, share a number of molecular features. The impact of these alterations for tumourigenesis and progression of the tumour has to be addressed in further studies, may be smoothing the way for enhanced therapeutic option in the near future.

\section{AUTHOR CONTRIBUTIONS}

All authors have read and approved the manuscript.

\section{CONFLICT OF INTEREST}

The authors declare no conflict of interest.

\section{REFERENCES}

Adzhubei IA, Schmidt S, Peshkin L, Ramensky VE, Gerasimova A, Bork P, Kondrashov AS, Sunyaev SR (2010) A method and server for predicting damaging missense mutations. Nat Methods 7(4): 248-249.

Asamura H, Kameya T, Matsuno Y, Noguchi M, Tada H, Ishikawa Y, Yokose T, Jiang SX, Inoue T, Nakagawa K, Tajima K, Nagai K (2006) Neuroendocrine neoplasms of the lung: a prognostic spectrum. J Clin Oncol 24(1): 70-76.

Beasley MB, Thunnissen FB, Brambilla E, Hasleton P, Steele R, Hammar SP, Colby TV, Sheppard M, Shimosato Y, Koss MN, Falk R, Travis WD (2000) Pulmonary atypical carcinoid: predictors of survival in 106 cases. Hum Pathol 31(10): 1255-1265.

Brambilla C, Fievet F, Jeanmart M, de Fraipont F, Lantuejoul S, Frappat V, Ferretti G, Brichon PY, Moro-Sibilot D (2003) Early detection of lung cancer: role of biomarkers. Eur Respir J Suppl 39: 36s-44s.

Capodanno A, Boldrini L, Ali G, Pelliccioni S, Mussi A, Fontanini G (2012) Phosphatidylinositol-3-kinase alpha catalytic subunit gene somatic 
mutations in bronchopulmonary neuroendocrine tumours. Oncol Rep 28(5): 1559-1566.

Cardillo G, Sera F, Di Martino M, Graziano P, Giunti R, Carbone L, Facciolo F, Martelli M (2004) Bronchial carcinoid tumors: nodal status and long-term survival after resection. Ann Thorac Surg 77(5): 1781-1785.

Colombo C, Minna E, Rizzetti MG, Romeo P, Lecis D, Persani L, Mondellini P, Pierotti MA, Greco A, Fugazzola L, Borrello MG (2015) The modifier role of RET-G691S polymorphism in hereditary medullary thyroid carcinoma: functional characterization and expression/penetrance studies. Orphanet $J$ Rare Dis 10: 25.

Couce ME, Bautista D, Costa J, Carter D (1999) Analysis of K-ras, N-ras, $\mathrm{H}-$ ras, and p53 in lung neuroendocrine neoplasms. Diagn Mol Pathol 8(2): 71-79.

Dabir S, Babakoohi S, Kluge A, Morrow JJ, Kresak A, Yang M, MacPherson D, Wildey G, Dowlati A (2014) RET mutation and expression in small-cell lung cancer. J Thorac Oncol 9(9): 1316-1323.

Engelman JA, Mukohara T, Zejnullahu K, Lifshits E, Borras AM, Gale CM, Naumov GN, Yeap BY, Jarrell E, Sun J, Tracy S, Zhao X, Heymach JV, Johnson BE, Cantley LC, Janne PA (2006) Allelic dilution obscures detection of a biologically significant resistance mutation in EGFRamplified lung cancer. J Clin Invest 116(10): 2695-2706.

Engle JA, Kolesar JM (2014) Afatinib: a first-line treatment for selected patients with metastatic non-small-cell lung cancer. Am J Health Syst Pharm 71(22): 1933-1938.

Esteller M, Sanchez-Cespedes M, Rosell R, Sidransky D, Baylin SB, Herman JG (1999) Detection of aberrant promoter hypermethylation of tumor suppressor genes in serum DNA from non-small cell lung cancer patients. Cancer Res 59(1): 67-70.

Fernandez-Cuesta L, Peifer M, Lu X, Sun R, Ozretic L, Seidel D, Zander T, Leenders F, George J, Muller C, Dahmen I, Pinther B, Bosco G, Konrad K, Altmuller J, Nurnberg P, Achter V, Lang U, Schneider PM, Bogus M, Soltermann A, Brustugun OT, Helland A, Solberg S, Lund-Iversen M, Ansen S, Stoelben E, Wright GM, Russell P, Wainer Z, Solomon B, Field JK, Hyde R, Davies MP, Heukamp LC, Petersen I, Perner S, Lovly CM, Cappuzzo F, Travis WD, Wolf J, Vingron M, Brambilla E, Haas SA, Buettner R, Thomas RK (2014) Frequent mutations in chromatinremodelling genes in pulmonary carcinoids. Nat Commun 5: 3518.

Fink G, Krelbaum T, Yellin A, Bendayan D, Saute M, Glazer M, Kramer MR (2001) Pulmonary carcinoid: presentation, diagnosis, and outcome in 142 cases in Israel and review of 640 cases from the literature. Chest 119(6): 1647-1651.

Futami H, Egawa S, Takasaki K, Tsukada T, Shiraishi M, Yamaguchi K (2003) Allelic loss of DNA locus of the RET proto-oncogene in small cell lung cancer. Cancer Lett 195(1): 59-65.

Garcia-Yuste M, Matilla JM, Cueto A, Paniagua JM, Ramos G, Canizares MA, Muguruza I (2007) Typical and atypical carcinoid tumours: analysis of the experience of the Spanish Multi-centric Study of Neuroendocrine Tumours of the Lung. Eur J Cardiothorac Surg 31(2): 192-197.

Glubb DM, Cerri E, Giese A, Zhang W, Mirza O, Thompson EE, Chen P, Das S, Jassem J, Rzyman W, Lingen MW, Salgia R, Hirsch FR, Dziadziuszko R, Ballmer-Hofer K, Innocenti F (2011) Novel functional germline variants in the VEGF receptor 2 gene and their effect on gene expression and microvessel density in lung cancer. Clin Cancer Res 17(16): 5257-5267.

Karachaliou N, Rosell R (2014) Systemic treatment in EGFR-ALK NSCLC patients: second line therapy and beyond. Cancer Biol Med 11(3): 173-181.

Krampitz GW, Norton JA (2014) RET gene mutations (genotype and phenotype) of multiple endocrine neoplasia type 2 and familial medullary thyroid carcinoma. Cancer 120(13): 1920-1931.

Kumar P, Henikoff S, Ng PC (2009) Predicting the effects of coding nonsynonymous variants on protein function using the SIFT algorithm. Nat Protoc 4(7): 1073-1081.

Leotlela PD, Jauch A, Holtgreve-Grez H, Thakker RV (2003) Genetics of neuroendocrine and carcinoid tumours. Endocr Relat Cancer 10(4): 437-450.

Lohmann DR, Fesseler B, Putz B, Reich U, Bohm J, Prauer H, Wunsch PH, Hofler H (1993) Infrequent mutations of the p53 gene in pulmonary carcinoid tumors. Cancer Res 53(23): 5797-5801.

McLaren W, Pritchard B, Rios D, Chen Y, Flicek P, Cunningham F (2010) Deriving the consequences of genomic variants with the Ensembl API and SNP Effect Predictor. Bioinformatics 26(16): 2069-2070.

Peifer M, Fernandez-Cuesta L, Sos ML, George J, Seidel D, Kasper LH, Plenker D, Leenders F, Sun R, Zander T, Menon R, Koker M, Dahmen I, Muller C, Di Cerbo V, Schildhaus HU, Altmuller J, Baessmann I, Becker C, de Wilde B,
Vandesompele J, Bohm D, Ansen S, Gabler F, Wilkening I, Heynck S, Heuckmann JM, Lu X, Carter SL, Cibulskis K, Banerji S, Getz G, Park KS, Rauh D, Grutter C, Fischer M, Pasqualucci L, Wright G, Wainer Z, Russell P, Petersen I, Chen Y, Stoelben E, Ludwig C, Schnabel P, Hoffmann H, Muley T, Brockmann M, Engel-Riedel W, Muscarella LA, Fazio VM, Groen H, Timens W, Sietsma H, Thunnissen E, Smit E, Heideman DA, Snijders PJ, Cappuzzo F, Ligorio C, Damiani S, Field J, Solberg S, Brustugun OT, Lund-Iversen M, Sanger J, Clement JH, Soltermann A, Moch H, Weder W, Solomon B, Soria JC, Validire P, Besse B, Brambilla E, Brambilla C, Lantuejoul S, Lorimier P, Schneider PM, Hallek M, Pao W, Meyerson M, Sage J, Shendure J, Schneider R, Buttner R, Wolf J, Nurnberg P, Perner S, Heukamp LC, Brindle PK, Haas S, Thomas RK (2012) Integrative genome analyses identify key somatic driver mutations of small-cell lung cancer. Nat Genet 44(10): 1104-1110.

Pelosi G, Scarpa A, Puppa G, Veronesi G, Spaggiari L, Pasini F, Maisonneuve P, Iannucci A, Arrigoni G, Viale G (2005) Alteration of the E-cadherin/betacatenin cell adhesion system is common in pulmonary neuroendocrine tumors and is an independent predictor of lymph node metastasis in atypical carcinoids. Cancer 103(6): 1154-1164.

Peng L, Song ZG, Jiao SC (2014) Efficacy analysis of tyrosine kinase inhibitors on rare non-small cell lung cancer patients harboring complex EGFR mutations. Sci Rep 4: 6104.

Pettitt AR, Sherrington PD, Stewart G, Cawley JC, Taylor AM, Stankovic T (2001) p53 dysfunction in B-cell chronic lymphocytic leukemia: inactivation of ATM as an alternative to TP53 mutation. Blood 98(3): 814-822.

Przygodzki RM, Finkelstein SD, Langer JC, Swalsky PA, Fishback N, Bakker A, Guinee DG, Koss M, Travis WD (1996) Analysis of p53, K-ras-2, and C-raf1 in pulmonary neuroendocrine tumors. Correlation with histological subtype and clinical outcome. Am J Pathol 148(5): 1531-1541.

Rea F, Rizzardi G, Zuin A, Marulli G, Nicotra S, Bulf R, Schiavon M, Sartori F (2007) Outcome and surgical strategy in bronchial carcinoid tumours: single institution experience with 252 patients. Eur J Cardiothorac Surg 31(2): 186-191.

Rekhtman N (2010) Neuroendocrine tumors of the lung: an update. Arch Pathol Lab Med 134(11): 1628-1638.

Reva B, Antipin Y, Sander C (2011) Predicting the functional impact of protein mutations: application to cancer genomics. Nucleic Acids Res 39(17): el18.

Revannasiddaiah S, Thakur P, Bhardwaj B, Susheela SP, Madabhavi I (2014) Pulmonary adenocarcinoma: implications of the recent advances in molecular biology, treatment and the IASLC/ATS/ERS classification. $J$ Thorac Dis 6(Suppl 5): S502-S525.

Rindi G, Petrone G, Inzani F (2014) The 2010 WHO classification of digestive neuroendocrine neoplasms: a critical appraisal four years after its introduction. Endocr Pathol 25(2): 186-192.

Rotondi M, Ercolino T, Fonte R, Lagonigro MS, Leporati P, Villani L, La Manna L, Mannelli M, Chiovato L (2009) Occurrence of medullary thyroid carcinoma, bronchial carcinoid tumor, and papillary thyroid carcinoma in a family bearing the RET G691S polymorphism. J Endocrinol Invest 32(2): 115-118.

Schulte KM, Machens A, Fugazzola L, McGregor A, Diaz-Cano S, Izatt L, Aylwin S, Talat N, Beck-Peccoz P, Dralle H (2010) The clinical spectrum of multiple endocrine neoplasia type $2 \mathrm{a}$ caused by the rare intracellular RET mutation S891A. J Clin Endocrinol Metab 95(9): E92-E97.

Scott WJ (2003) Surgical treatment of other bronchial tumors. Chest Surg Clin N Am 13(1): 111-128.

Sequist LV, Waltman BA, Dias-Santagata D, Digumarthy S, Turke AB, Fidias P, Bergethon K, Shaw AT, Gettinger S, Cosper AK, Akhavanfard S, Heist RS, Temel J, Christensen JG, Wain JC, Lynch TJ, Vernovsky K, Mark EJ, Lanuti M, Iafrate AJ, Mino-Kenudson M, Engelman JA (2011) Genotypic and histological evolution of lung cancers acquiring resistance to EGFR inhibitors. Sci Transl Med 3(75): 75ra26.

Sos ML, Levin RS, Gordan JD, Oses-Prieto JA, Webber JT, Salt M, Hann B, Burlingame AL, McCormick F, Bandyopadhyay S, Shokat KM (2014) Oncogene mimicry as a mechanism of primary resistance to BRAF inhibitors. Cell Rep 8(4): 1037-1048.

Swarts DR, Henfling ME, Van Neste L, van Suylen RJ, Dingemans AM, Dinjens WN, Haesevoets A, Rudelius M, Thunnissen E, Volante M, Van Criekinge W, van Engeland M, Ramaekers FC, Speel EJ (2013) CD44 and OTP are strong prognostic markers for pulmonary carcinoids. Clin Cancer Res 19(8): 2197-2207. 
Swarts DR, Ramaekers FC, Speel EJ (2012) Molecular and cellular biology of neuroendocrine lung tumors: evidence for separate biological entities. Biochim Biophys Acta 1826(2): 255-271.

Takei H, Asamura H, Maeshima A, Suzuki K, Kondo H, Niki T, Yamada T, Tsuchiya R, Matsuno Y (2002) Large cell neuroendocrine carcinoma of the lung: a clinicopathologic study of eighty-seven cases. J Thorac Cardiovasc Surg 124(2): 285-292.

Thomas Jr CF, Tazelaar HD, Jett JR (2001) Typical and atypical pulmonary carcinoids: outcome in patients presenting with regional lymph node involvement. Chest 119(4): 1143-1150.

Travis WD (2009) Lung tumours with neuroendocrine differentiation. Eur J Cancer 45(Suppl 1): 251-266.

Travis WD, Rush W, Flieder DB, Falk R, Fleming MV, Gal AA, Koss MN (1998) Survival analysis of 200 pulmonary neuroendocrine tumors with clarification of criteria for atypical carcinoid and its separation from typical carcinoid. Am J Surg Pathol 22(8): 934-944.

Travis WD. World Health Organization, International Agency for Research on Cancer, International Association for the Study of Lung Cancer,
International Academy of Pathology (2004) Pathology and Genetics of Tumours of the Lung, Pleura, Thymus and Heart. IARC Press Oxford University Press (distributor): Lyon, Oxford.

Wang Y, Zheng Y, Zhang W, Yu H, Lou K, Zhang Y, Qin Q, Zhao B, Yang Y, Hui R (2007) Polymorphisms of KDR gene are associated with coronary heart disease. J Am Coll Cardiol 50(8): 760-767.

Yeganeh MZ, Sheikholeslami S, Hedayati M (2015) RET proto oncogene mutation detection and medullary thyroid carcinoma prevention. Asian Pac J Cancer Prev 16(6): 2107-2117.

Zochbauer-Muller S, Fong KM, Virmani AK, Geradts J, Gazdar AF, Minna JD (2001) Aberrant promoter methylation of multiple genes in non-small cell lung cancers. Cancer Res 61(1): 249-255.

This work is published under the standard license to publish agreement. After 12 months the work will become freely available and the license terms will switch to a Creative Commons AttributionNonCommercial-Share Alike 4.0 Unported License.

Supplementary Information accompanies this paper on British Journal of Cancer website (http://www.nature.com/bjc) 